\title{
Intravenous sedation prior to peribulbar anaesthesia for cataract surgery in elderly patients
}

David H.W. Wong MB BS FRCPC, Pamela M. Merrick BSN
Conclusion: Intravenous sedation with midazolam or alfentanil or in combination reduced pain perception, pain recall, and haemodynamic responses from peribulbar anaesthesia. Fifteen percent of patients given alfentanil developed clinically important oxygen desaturation. The use of fine gauge needles combined with slow injection of anaesthetic solution causes minimal discomfort, and routine iv sedation may be unnecessary.

Objectif: Étudier si, avant un bloc péribulbaire, la sédation iv au midazolam, à l'alfentanil ou à la combinaison midazolamalfentanil diminue la douleur, réduit son évocation et atténue les réponses hémodynamiques; déterminer si d'autres facteurs que la sédation iv influencent la saturation en oxygène $\left(\mathrm{SpO}_{2}\right)$. Méthodes: Au cours d'une étude aléatoire, en double aveugle et contrôlée par placebo, 120 patients âgés en moyenne de 73 ans subissant une intervention pour cataracte sous anesthésie péribulbaire ont été répartis pour recevoir soit du sol physiologique, du midazolam $1 \mathrm{mg}$, de l'alfentanil $500 \mu \mathrm{g}$ ou du midazolam $0,5 \mathrm{mg}$ associé à $250 \mu \mathrm{g}$ d'alfentanil. La pression artérielle (PA), la fréquence cardiaque $(F C)$ et l'oxymétrie de pouls ont été enregistrées avant l'injection des produits à l'étude, immédiatement après la complétion du bloc péribulbaire et dix minutes plus tard. La douleur associée au bloc était évaluée sur une échelle visuelle analogique immédiatement après le bloc et après l'intervention. L'évocation de la douleur était cotée au téléphone un jour après l'intervention.

Résultats: Les scores de douleur étaient bas pour les quatre groupes. Le midazolam-alfentanil a réduit la perception de la douleur et tous les produits ont diminué son évocation. Le midazolam a fait baisser la $T A ;$ l'alfentanil \pm midazolam a ralenti la FC. Tous les produits ont réduit la $\mathrm{SpO}_{2}$ plus que le sol. physiologique mais, en général, à un niveau cliniquement sans importance. Neuf patients ont présenté une $\mathrm{SpO}_{2} \leq 90 \%$ et tous avaient reçu de l'alfentanil avec ou sans midazolam. Il a été impossible de prédire le niveau de saturation en oxygène par d'autres facteurs que la sédation iv et le niveau initial de la $\mathrm{SpO}$.

Conclusion: La sédation intraveineuse au midazolam, à l'alfentanil ou à leur association diminue la perception de la 
douleur, son évocation et les réponses hémodynamiques provoquées par l'anesthésie péribulbaire. Quinze pour cent des patients sous alfentanil se sont désaturés de façon cliniquement importante. L'utilisation d'aiguilles fines associée et le lenteur de l'injection de la solution anesthésique permettent de diminuer la souffrance provoquée par le bloc; une sédation iv systématique n'est pas absolument nécessaire.

Cataract surgery, a common operation in the elderly, is frequently performed under regional anaesthesia. Since the anaesthetic virtually eliminates pain during surgery, the most unpleasant memory of the operation in many patients is the pain associated with needle insertion or discomfort during injection of the anaesthetic solution.

Routine oral and/or $i v$ sedation is commonly used to minimize the pain and discomfort associated with eye block anaesthesia. A preliminary survey (unpublished data) in the Vancouver Hospital Eye Care Centre over 12 mo showed that only $18 \%$ of patients were given $i v$ sedation, and $90 \%$ of these were on patient request or because of obvious anxiety. In the majority of patients, the sedative drugs were given prior to performing the blocks. Midazolam was used alone in $72.5 \%$, midazolam plus fentanyl or alfentanil in $23.5 \%$, and fentanyl or alfentanil alone in $4 \%$ of patients. Fentanyl and alfentanil were used with equal frequency. When used alone, the usual doses were $1 \mathrm{mg}$ midazolam, $50 \mu \mathrm{g}$ fentanyl, or $500 \mu \mathrm{g}$ alfentanil. When used in combination, $1 \mathrm{mg}$ midazolam was usually used with 25 to $50 \mu \mathrm{g}$ fentanyl, or 250 to $500 \mu \mathrm{g}$ alfentanil.

The primary goal of this study was to assess if $i v$ sedation (using midazolam, alfentanil, or midazolamalfentanil combination) prior to peribulbar anaesthesia (1) minimizes the pain or discomfort, (2) reduces pain recall, (3) attenuates the haemodynamic responses to the performance of the eye block, and (4) has an unfavourable effect on oxygenation, when compared with placebo (saline).

\section{Methods}

This randomized, double blind, placebo-controlled study was approved by university and hospital ethics committees for research and other studies involving human subjects. All patients having cataract surgery under regional eye blocks in the ambulatory Vancouver Hospital Eye Care Centre Operating Room Suite were eligible for recruitment. Patients who had dementia, confusion, blindness of the unoperated eye, known allergy or adverse reaction to midazolam or alfentanil, advanced pulmonary disease, oxygen desaturation on room air $\left(\mathrm{SpO}_{2}<93 \%\right)$, or taking $\beta$-blocker medications were excluded. Any patient who requested sedation was excluded from the study.

The preoperative history, physical examination, appropriate laboratory data (ECG, CBC, electrolytes) and written informed consent were obtained before surgery. An intravenous catheter with a heparin-lock was inserted. Routine monitoring included ECG, pulse oximetry, and non-invasive blood pressure. A total of 120 patients were assigned using a randomization table into four groups to receive one of the following: (1) normal saline, (2) $1 \mathrm{mg}$ midazolam, (3) $500 \mu \mathrm{g}$ alfentanil, and (4) $0.5 \mathrm{mg}$ midazolam and $250 \mu \mathrm{g}$ alfentanil. All medications were given in $1 \mathrm{ml}$ volume in a $3 \mathrm{ml}$ syringe, prepared by an assistant not involved in the study, and the contents were unknown to the investigator. After injecting the study medication, the catheter and heparin-lock were flushed with $2 \mathrm{ml}$ normal saline. A two-injection peribulbar block using a sharp 27-gauge needle and a total of $7 \mathrm{ml}$ of a 1:1 mixture of lidocaine $2 \%$ and bupivacaine $0.75 \%$ plus hyaluronidase 7.5 units $\cdot \mathrm{ml}^{-1}$ was performed five minutes after the injection of study medication.

Blood pressure, heart rate and pulse oximetry readings were recorded (1) before injection of study drug, (2) immediately after completion of the peribulbar block, and (3) 10 min after the block. The patients' perception of pain from the anaesthetic block was assessed using a visual analogue scale (VAS, 0-10) (1) immediately after the block, and (2) immediately after surgery. In addition, their recall of pain was assessed on the postoperative day by telephone using descriptive terms: none/cannot recall, minimal, mild, moderate or severe. The patients' overall satisfaction with the anaesthetic was assessed (1) immediately after the block, (2) immediately after surgery, and (3) on the postoperative day. Verbal stimulation and supplemental oxygen by mask were applied to patients who had $\mathrm{SpO}_{2}<93 \%$.

\section{Statistical analysis}

Pre-study power calculation determined that 17 patients in each group were needed to ensure a power of $80 \%$ to find a mean difference of one between treatment and control groups in VAS pain score, and a within group standard deviation of one, using an alpha of 0.05 . Statistical analysis was performed using the Number Cruncher Statistical System (NCSS) computer program, version 5.03. Martinez-Iglewicz, Kolmogorov-Smirnov, and D'Agostino-Pearson Omnibus $\mathrm{K}^{2}$ normality tests were used to determine normality of data distributions.

Categorical data including race, gender, medical problems, ASA physical status, block supplementation, pain recall, and patient satisfaction were analyzed for between group differences using chi-square analysis. 
TABLE I Patient demographics

\begin{tabular}{lcccc}
\hline & Saline & Midazolam & Alfentanil & Midazolam-alfentanil \\
\hline Male/female & $10 / 20$ & $10 / 20$ & $15 / 15$ & $11 / 19$ \\
Caucasian/Oriental & $15 / 15$ & $21 / 9$ & $14 / 16$ & $18 / 12$ \\
Age (yr) (mean \pm SD) & $73 \pm 9$ & $73 \pm 5.6$ & $73 \pm 10.9$ & $72 \pm 8.3$ \\
Weight $(\mathrm{kg})$ (mean \pm SD) & $64 \pm 17.7$ & $62 \pm 14$ & $62 \pm 12.2$ & $66 \pm 15.7$ \\
Height (cm) (mean \pm SD) & $160 \pm 10$ & $157 \pm 11.6$ & $161 \pm 10.6$ & $161 \pm 12.4$ \\
Hypertension & 12 & 11 & 8 & 12 \\
Diabetes & 5 & 5 & 2 & 4 \\
ASHD & 4 & 4 & 1 & 5 \\
COPD & 3 & 4 & 2 & 1 \\
ASA I & 1 & 4 & 4 & 2 \\
ASA II & 23 & 22 & 19 & 22 \\
ASA III & 6 & 4 & 7 & 6 \\
\hline
\end{tabular}

ASHD - atherosclerotic heart disease.

COPD - chronic obstructive pulmonary disease.

Fisher's exact tests with Bonferroni's correction were used for pairwise comparisons between the four groups when a significant difference was found by the overall chi-square test. Age, weight, and height were analyzed using one-way ANOVA. VAS pain scores after block and after surgery were analyzed using Kruskal-Wallis tests, with Dunn's test post hoc for multiple comparisons due to skewness of their distributions. Blood pressure, heart rate, and $\mathrm{SpO}_{2}$ at pre-, post-, and 10-min post-block were analyzed using two factor repeated measures ANOVA, followed by paired $t$ tests with Bonferroni's correction to examine change over time within each group. One-way ANOVAs and StudentNewman-Keul's (SNK) tests were applied at each time point to compare the four groups.

Relationships between the lowest $\mathrm{SpO}_{2}$ and the dose of midazolam or alfentanil, age, weight, and baseline $\mathrm{SpO}_{2}$ were tested using stepwise multiple regression. Relationships between the lowest $\mathrm{SpO}_{2}$ and medical problems, gender, race, ASA status, and the study drug groups, were tested by factorial ANOVA, followed by SNK tests, as appropriate. $P<0.05$ was considered significant except where Bonferroni's correction was used.

\section{Results}

Demographic data are shown in Table I. No demographic differences were found among the groups. In the midazolam group, the dose of midazolam used was 16.8 $\pm 4 \mu \mathrm{g} \cdot \mathrm{kg}^{-1}$. In the alfentanil group, the dose of alfentanil was $8.4 \pm 1.9 \mu \mathrm{g} \cdot \mathrm{kg}^{-1}$. In the midazolam-alfentanil combination group, the dose of the midazolam component was $7.9 \pm 1.8 \mu \mathrm{g} \cdot \mathrm{kg}^{-1}$, and that of alfentanil component was $3.95 \pm 0.89 \mu \mathrm{g} \cdot \mathrm{kg}^{-1}$.

To achieve perfect akinesis, a supplementary retrobulbar block was used in 19 patients $(15.8 \%)$. There was no difference among the groups in supplementation requirements. No patient required further supplemental anaesthesia or sedation intraoperatively, or felt pain during surgery.

The haemodynamic and $\mathrm{SpO}_{2}$ changes are shown in Table II. Midazolam reduced the systolic blood pressure immediately after $(P<0.001)$ and $10 \mathrm{~min}$ after $(P<$ 0.0001 ) the administration of eye blocks. Alfentanil with or without midazolam reduced the heart rate immediately $(P<0.05$ and $P<0.001$, respectively) and 10 minutes after $(P<0.0001$ for both) the blocks. After any of the iv sedation, the $\mathrm{SpO}_{2}$ was lower when measured immediately and $10 \mathrm{~min}$ after the blocks, compared with placebo $(P<0.05)$.

Two patients, one in the alfentanil group, and the other in the midazolam-alfentanil group, fell asleep before surgery. Both patients developed $\mathrm{SpO}_{2} \leq 90 \%$. They were easily aroused, with immediate improvement of oxygen saturation. No patient experienced nausea or vomiting.

The patients' assessment of pain associated with the performance of the anaesthetic is summarized in Table III. The overall median pain scores were low. Midazolam-alfentanil combination was associated with a lower pain score both immediately after the block $(P<$ $0.05)$ and after surgery $(P<0.001)$, when compared with saline. Post hoc power calculations determined that the study had a power of 0.93 to find a mean difference of one in VAS pain scores between treatment groups and the control group, using an alpha of 0.025 . Intravenous sedation, using midazolam, alfentanil, or in combination, was associated with more patients who did not recall pain from the anaesthetic block when asked on the day following surgery $(P<0.00001, P<0.01$ and $P<0.001$, respectively)

All patients, except two in the saline group, were completely satisfied with the anaesthetic management 
TABLE II Haemodynamic and $\mathrm{SpO}_{2}$ changes

\begin{tabular}{llcccc}
\hline & & Saline & Midazolam & Alfentanil & Mid-Alf \\
\hline SBP & Pre-block & $152 \pm 26.6$ & $154 \pm 25.5$ & $153 \pm 21.6$ & $147 \pm 20.5$ \\
& Post-block & $154 \pm 26.3$ & $144 \pm 20.2^{*}$ & $155 \pm 23$ & $140 \pm 22.2$ \\
& 10 min post-block & $153 \pm 28$ & $142 \pm 19.7^{*}$ & $150 \pm 23.4$ & $141 \pm 20.6$ \\
DBP & Pre-block & $82 \pm 16$ & $81 \pm 16.6$ & $83 \pm 11.5$ & $79 \pm 12.4$ \\
& Post-block & $82 \pm 18$ & $79 \pm 14.7$ & $82 \pm 11.6$ & $77 \pm 15.4$ \\
& 10 min post-block & $84 \pm 19$ & $78 \pm 12.8$ & $83 \pm 13$ & $75 \pm 15$ \\
& & & & $72 \pm 13.5$ & $72 \pm 11.7$ \\
HR & Pre-block & $69 \pm 14.7$ & $80 \pm 14.3 \dagger$ & $69 \pm 11.6^{*}$ & $69 \pm 11^{*}$ \\
& Post-block & $69 \pm 15.5$ & $78 \pm 14.6$ & $67 \pm 11.1^{*}$ & $67 \pm 11.1^{*}$ \\
& 10 min post-block & $67 \pm 14.8$ & $75 \pm 13.7$ & & $96 \pm 2$ \\
SpO & & $97.4 \pm 1.6$ & $97 \pm 1.7$ & $97 \pm 1.5$ & $(93-99)$ \\
& Pre-block & $(94-99)$ & $(93-100)$ & $(93-100)$ & $95 \pm 2.2 \ddagger$
\end{tabular}

Systolic BP (SBP) and Diastolic BP (DBP) are expressed as mean \pm SD.

$\mathrm{SpO}_{2}$ is expressed as mean $\pm \mathrm{SD}$, and range.

$* P<0.05$, versus pre-block.

$\dagger P<0.05$, versus all other groups.

$\ddagger P<0.05$, versus saline group.

TABLE III Patients' assessment of pain associated with anaesthetic block

\begin{tabular}{llllll}
\hline & & Saline & Midazolam & Alfentanil & Mid-Alf \\
\hline $\begin{array}{l}\text { Pain score median } \\
\text { (range) }\end{array}$ & After block & $1.35(0-4)$ & $1.2(0-3)$ & $0.9(0-3)$ & $0.6(0-2.8)$ \\
& After surgery & $1.2(0-4)$ & $0.5(0-2.5)$ & $0.5(0-2.3)$ & $0.3(0-2)$ \\
Pain recall & & & & & \\
(Number of patients) & Mone & 8 & $26^{*}$ & $19^{*}$ & $25^{*}$ \\
& Minimal & 16 & 4 & 10 & 4 \\
& Mild & 6 & 0 & 1 & 1 \\
& Moderate & 0 & 0 & 0 & 0 \\
& Severe & 0 & 0 & 0 & 0 \\
\hline
\end{tabular}

$* P<0.05$, versus saline group.

TABLE IV Prediction of Lowest $\mathrm{SpO}_{2}$ based on pre-block $\mathrm{SpO}_{2}$

\begin{tabular}{llll}
\hline All patients & $n=120$ & $\mathrm{y}=2.7+0.94 \mathrm{x}$ & $\mathrm{r}=0.6192 *$ \\
Saline Group & $n=30$ & $\mathrm{y}=-6.12+1.05 \mathrm{x}$ & $\mathrm{r}=0.8455 *$ \\
Midazolam Group & $n=30$ & $\mathrm{y}=23.4+0.73 \mathrm{x}$ & $\mathrm{r}=0.6602$
\end{tabular}$*$

$* P<0.05$.

when questioned immediately after the peribulbar block. Two patients in the saline group were satisfied with reservation. Although there was minimal discomfort with the anaesthetic block, they would have preferred to have been asleep. Neither patient had requested sedation intraoperatively. All patients were completely satisfied with the anaesthetic when questioned after surgery, and when asked on the day following surgery.

Age, weight, and dose of midazolam or alfentanil were not predictive of lowest $\mathrm{SpO}_{2}$. However, pre-block $\mathrm{SpO}_{2}$ was found to have a positive linear relationship predictive of lowest $\mathrm{SpO}_{2}$ levels $(\mathrm{y}=2.7+0.9 \mathrm{x}, \mathrm{r}=$ 0.6192 ) overall and within groups (Table IV). Sex, race, ASA status, and medical problems were not predictive of lowest $\mathrm{SpO}_{2}$ levels. However, there was a significant relationship found between study group and lowest $\mathrm{SpO}_{2}(P=0.0003)$. The $i v$ sedation groups were each found to have lower mean $\mathrm{SpO}_{2}$ levels than the saline group (Table II). There were no interactions among the factors. These lowest mean $\mathrm{SpO}_{2}$ levels did not reach clinically important levels of desaturation, but nine patients had $\mathrm{SpO}_{2} \leq 90 \%$. No patient who received $1 \mathrm{mg}$ 
midazolam $i v$ developed $\mathrm{SpO}_{2} \leq 90 \%$. Seven patients who received $500 \mu \mathrm{g}$ alfentanil $i v$ and two patients who received a combination of midazolam $0.5 \mathrm{mg}$ and alfentanil $250 \mu \mathrm{g}$ developed hypoxaemia with $\mathrm{SpO}_{2} \leq 90 \%$. The incidence of hypoxaemia was higher in the alfentanil group than in the midazolam or placebo groups $(P$ $=0.0105$ ).

\section{Discussion}

Although iv sedation is used in only $18 \%$ of patients undergoing cataract surgery in the Vancouver Hospital Eye Care Centre, the routine use of sedation in conjunction with ocular block anaesthesia is common practice in other centres. Oral sedation is frequently given 45 min to one hour preoperatively, using diazepam, ${ }^{1}$ diazepam or barbiturate plus promethazine, ${ }^{2}$ or an assortment of oral agents. ${ }^{3}$ Many authors reported the routine use of $i v$ sedation, such as fentanyl and/or midazolam, ${ }^{4,5}$ droperidol, fentanyl and diazepam, ${ }^{6}$ midazolam-fentanyl or methohexitone-fentanyl combinations, ${ }^{7}$ or fentanyl and droperidol. ${ }^{8}$ A combination of oral lorazepam and $i v$ fentanyl is also used. ${ }^{9}$

The effect of sedation in conjunction with ocular block anaesthesia has been the subject of several studies. Salmon et al. ${ }^{10}$ showed that in patients who had received temazepam and metoclopramide given orally two hours before surgery, additional sedation with continuous infusion of midazolam or propofol during surgery under peribulbar anaesthesia did not provide any additional benefit. Virkkila et al. ${ }^{11}$ reported that in elderly patients undergoing ambulatory cataract surgery under eye block anaesthesia, alfentanil $\left(12.5 \mu \mathrm{g} \cdot \mathrm{kg}^{-1}\right)$ or midazolam $\left(20 \mu \mathrm{g} \cdot \mathrm{kg}^{-1}\right)$ im produced sedative effects, but was associated with a reduction of oxygen saturation. We are not aware of any study that assessed the effectiveness of $i v$ sedation in reducing pain, discomfort and pain during peribulbar anaesthesia.

Midazolam, the most commonly used sedative drug in our institution $(72.5 \%$ of instances where $i v$ sedation was employed), was used because of its short duration of action, which makes it suitable for reducing anxiety in elderly ambulatory patients. ${ }^{12}$ It may reduce pain on injection and produce intraoperative amnesia, ${ }^{13}$ although a dose-related antagonism of the effects of opioids has been shown in mice. ${ }^{14}$ In healthy volunteers, $i v$ midazolam given in conscious sedation doses reduces the affective and motivational component of the pain experience. ${ }^{15}$ Memory may be impaired at the time of discharge after sedation with iv midazolam. ${ }^{16}$ There is, however, a wide variation in sensitivity of patients to midazolam. ${ }^{17}$ In young, healthy volunteers, it has been shown that electrophysiological and motor responses may still be impaired $50 \mathrm{~min}$ after the $i v$ infusion of 70 $\mu \mathrm{g} \cdot \mathrm{kg}^{-1}$ midazolam, although routine clinical examination may be normal. ${ }^{18}$ In the present study, midazolam attenuated the haemodynamic responses associated with the performance of peribulbar anaesthesia, and reduced recall of discomfort or pain. It is interesting to note that Ferrari and Donlon ${ }^{19}$ observed that grimacing or verbal response during the administration of eye blocks under $i v$ sedation do not predict or correlate with patient recall.

Alfentanil was used for this study because of its analgesic properties and short duration of action. The doses reduced pain perception and recall of the peribulbar anaesthesia.

In the present study, $15 \%$ of those receiving alfentanil or alfentanil-midazolam combination developed oxygen desaturation with $\mathrm{SpO}_{2} \leq 90 \%$. Sex, race, age, weight, presence of chronic obstructive pulmonary disease or other medical problems, ASA physical classification, and the dose of sedative drugs were not helpful in predicting oxygen saturation levels. Baseline $\mathrm{SpO}_{2}$, however, was predictive of oxygen saturation.

Even in young, fit, adult patients, iv sedation with midazolam has been reported to cause transient oxygen desaturation..$^{20}$ The dose of midazolam used in this study ( $1 \mathrm{mg}$, or an average of $16.8 \mu \mathrm{g} \cdot \mathrm{kg}^{-1}$ ) was found to be effective, and is lower than those used in. most reports. ${ }^{12,13,18,20,21}$ None of the patients who received midazolam alone in the present study developed severe oxygen desaturation that was observed only in patients who received alfentanil alone or in combination with midazolam.

Pain and discomfort during the performance of eye blocks can result from insertion of the needle or injection of the anaesthetic solution. Pain from needle insertion can be virtually eliminated by topical anaesthesia of the conjunctiva before inserting the needle through the conjunctival fornix or at the medial canthus. ${ }^{22}$ The use of a fine-gauge needle does not usually cause pain during insertion through the eyelid. In most cases, the injection of anaesthetic solution causes the discomfort and this can be minimized by injecting slowly. The low pain scores, lack of haemodynamic changes such as hypertension and tachycardia, and the high patient acceptability seen in this study, even in the placebo group, supports the belief that ocular block may be performed with minimal pain and discomfort.

In summary, this study demonstrates that in elderly patients, iv midazolam-alfentanil combination reduced the perception of pain associated with the performance of eye blocks, and attenuated haemodynamic responses. However, with gentle insertion of a fine-gauge needle and slow injection of anaesthetic solution, pain scores were low and haemodynamic responses not significant even in the placebo group. Nevertheless, the use of iv 
sedation with midazolam, alfentanil, or midazolamalfentanil combination reduced the recall of pain from the performance of peribulbar anaesthesia when assessed on the day following surgery. However, $15 \%$ of patients receiving alfentanil, alone or in combination with midazolam, developed severe oxygen desaturation with $\mathrm{SpO}_{2} \leq 90 \%$. It was not possible to predict oxygen saturation after receiving $i v$ sedation, except by baseline $\mathrm{SpO}_{2}$ levels.

Routine oral or $i v$, or combination of oral and $i v$, sedation for patients having eye surgery under local anaesthesia is a common practice. In our institution, $i v$ sedation is used only when indicated, or at patient's request. We suggest that routine sedation is not necessary when gentle techniques are used for peribulbar anaesthesia in elderly patients undergoing cataract surgery. When $i v$ sedation is required, small doses of midazolam may be preferable to alfentanil, as it is less likely to lead to severe oxygen desaturation.

\section{Acknowledgement}

We sincerely thank Janet Lee Haines for her technical advice and support.

\section{References}

1 Spencer $M F$. Extracapsular cataract and lens implant surgery in developing countries: keeping it simple. Ophthalmic Surgery 1990; 21: 447-52.

2 Quist LH, Stapleton SS, McPherson SD Jr. Preoperative use of the Honan intraocular pressure reducer. Am J Ophthalmol 1983; 95: 536-8.

3 Smith PH, Kemp P, Smith ER. A comparison of retrobulbar block produced by etidocaine $1 \%$ and by a mixture of lidocaine $2 \%$ and bupivacaine $0.75 \%$. Ophthalmic Surgery 1987; 18: 106-10.

4 Palay DA, Stulting RD. The effect of external ocular compression on intraocular pressure following retrobulbar anesthesia. Ophthalmic Surgery 1990; 21: 503-7.

5 Cheng $K P$, Larson CE, Biglan AW, D'Antonio JA. A prospective, randomized, controlled comparison of retrobulbar and general anesthesia for strabismus surgery. Ophthalmic Surgery 1992; 23: 585-90.

6 Fiore PM, Cinotti AA. Systemic effects of intraocular epinephrine during cataract surgery. Annals of Ophthalmology 1988; 20: $23-5$.

7 Sabo B, Smith RB, Gilbert TJ. Evaluation of rebreathing in patients undergoing cataract surgery. Ophthalmic Surgery 1988; 19: 249-51.

8 Zahl K, Jordan A, McGroarty J, Sorensen B, Gotta AW. Peribulbar anesthesia. Effect of bicarbonate on mixtures of lidocaine, bupivacaine, and hyaluronidase with or without epinephrine. Ophthalmology 1991; 98: 239-42.

9 Sarvela J, Nikki P. Hyaluronidase improves regional oph- thalmic anaesthesia with etidocaine. Can J Anaesth 1992; 39: 920-4.

10 Salmon JF, Mets B, James MF, Murray AD. Intravenous sedation for ocular surgery under local anaesthesia. Br J Ophthalmol 1992; 76: 598-601.

11 Virkkila ME, Ali-Melkkila TM, Kanto JH. Premedication for outpatient cataract surgery: a comparative study of intramuscular alfentanil, midazolam and placebo. Acta Anaesthesiol Scand 1992; 36: 559-63.

12 Nuotto EJ, Korttila KT, Lichtor JL, Östman PL, Rupani G. Sedation and recovery of psychomotor function after intravenous administration of various doses of midazolam and diazepam. Anesth Analg 1992; 74: 265-71.

13 White $P F$, Negus $J B$. Sedative infusions during local and regional anesthesia: a comparison of midazolam and propofol. J Clin Anesth 1991; 3: 32-9.

14 Rosland $\mathrm{JH}$, Hole $K$. 1,4-Benzodiazepines antagonize opiate-induced antinociception in mice. Anesth Analg 1990; 71:242-8.

15 Coulthard P, Rood JP. An investigation of the effect of midazolam on the pain experience. $\mathrm{Br} \mathrm{J}$ Oral Maxillofac Surg 1992; 30: 248-51.

16 Ho ET, Parbrook GD, Still DM, Parbrook EO. Memory function after i.v. midazolam or inhalation of isoflurane for sedation during dental surgery. Br J Anaesth 1990; 64: $337-40$.

17 Richards A, Griffiths M, Scully C. Wide variation in patient response to midazolam sedation for outpatient oral surgery. Oral Surgery, Oral Medicine, Oral Pathology 1993; 76: 408-11.

18 Reinsel RA, Veselis RA, Heino R, Miodownik S, Alagesan $R$, Bedford $R F$. Effect of midazolam on the auditory event-related potential: measures of selective attention. Anesth Analg 1991; 73: 612-8.

19 Ferrari LR, Donlon JV. A comparison of propofol, midazolam, and methohexital for sedation during retrobulbar and peribulbar block. J Clin Anesth 1992; 4: 93-6.

20 Zacharias M, Luyk NH, Parkinson RT. Oxygen saturation during intravenous sedation using midazolam. New Zealand Dental Journal 1992; 88: 94-6.

21 van der Bijl P, Roelofse JA, Joubert JJ, van Zyl JF. Comparison of various physiologic and psychomotor parameters in patients sedated with intravenous lorazepam, diazepam, or midazolam during oral surgery. J Oral Maxillofac Surg 1991; 49: 672-8.

22 Lewis $P$, Hamilton $R C$, Brant $R$, Loken $R G$, Maltby $J R$, Strunin $L$. Comparison of plain with $\mathrm{pH}$-adjusted bupivacaine with hyaluronidase for peribulbar block. Can J Anaesth 1992; 39: 555-8. 